


\section{DISCLAIMER}

This report was prepared as an account of work sponsored by an agency of the United States Government. Neither the United States Government nor any agency Thereof, nor any of their employees, makes any warranty, express or implied, or assumes any legal liability or responsibility for the accuracy, completeness, or usefulness of any information, apparatus, product, or process disclosed, or represents that its use would not infringe privately owned rights. Reference herein to any specific commercial product, process, or service by trade name, trademark, manufacturer, or otherwise does not necessarily constitute or imply its endorsement, recommendation, or favoring by the United States Government or any agency thereof. The views and opinions of authors expressed herein do not necessarily state or reflect those of the United States Government or any agency thereof. 


\section{DISCLAIMER}

Portions of this document may be illegible in electronic image products. Images are produced from the best available original document. 
Printed in the United States of America Available from

National Technical Information Service

U. S. Department of Commerce

5285 Port Royal Road

Springfield, VA 22161

NTIS price codes

Printed copy: $\mathrm{A} 03$

Microfiche copy: A01

This report was prepared as an account of work sponsored by an agency of the United States Government. Neither the United States Government nor any agency thereof, nor any of their employees, makes any warranty, express or implied, or assumes any legal liability or responsibility for the accuracy, completeness, or usefulness of any information, apparatus, product, or process disclosed, or represents that its use would not infringe privately owned rights. Reference herein to any specific commercial product, process, or service by trade name, trademark, manufacturer, or otherwise, does not necessarily constitute or imply its endorsement, recommendation, or favoring by the United States Government or any agency thereof. The views and opinions of authors expressed herein do not necessarily state or reflect those of the United States Government or any agency thereof. 
Date of Issue: September 30, 1980

Distribution Category: UC-38

\title{
ELECTROCHEMICAL MACHINING IN-PROCESS DATA COLLECTION AND CONTROL
}

\author{
R. E. Neal
}

Fabrication Systems Department $Y=12$ Devolopment Division

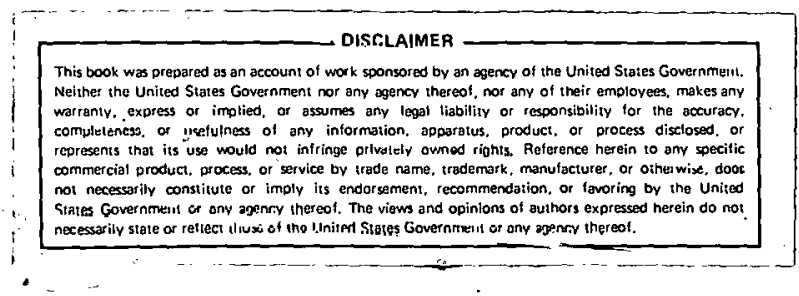

Oak Ridge Y-12 Plant

P. O. Box Y, Oak Ridạe, Tennessee 37830

Prepared for the Department of Energy

Under US Government Contract W-7405-eng-28 


\begin{abstract}
Electrochemical machining (ECM) is a fast and efficient method to fabricate intricate metal parts. However, tooling is often expensive; and electrical power consumption is relatively high. The precision of an ECM process is dependent upon several variables which often cannot be predicted in the initial tool design. This leads to iterative tool adjustments until the desired level of precision is achieved. A system. was devised to use a computer for collecting data from the ECM process and for monitoring and controlling ECM operations. It is believed that these data collections and analyses will lead to the formulation of algorithms to produce parts with better tolerances and will allow more efficient uses of the ECM machines. One algorithm has been developed to allow the efficient ECM of large-surface-area parts. Such programs and equipment will enhance the competitive position of the ECM process in machining applications previously performed by more conventional methods while minimizing electrical power consumption.
\end{abstract}




\section{CONTENTS}

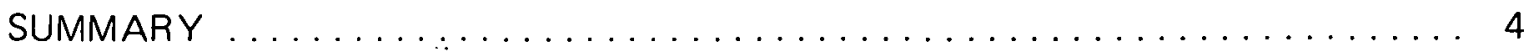

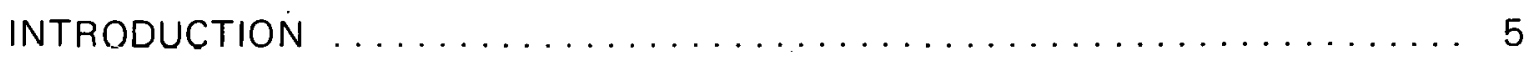

IN-PROCESS DATA COLLECTIONN AND CONTROL $\ldots \ldots \ldots \ldots \ldots \ldots \ldots \ldots$

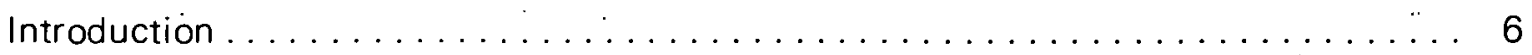

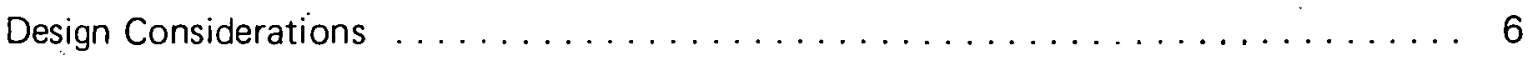

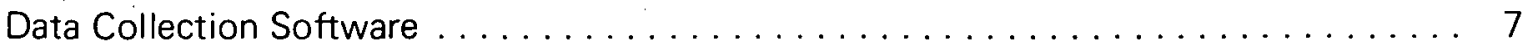

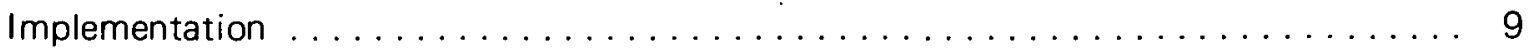

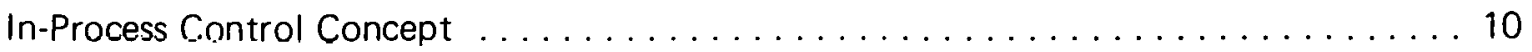

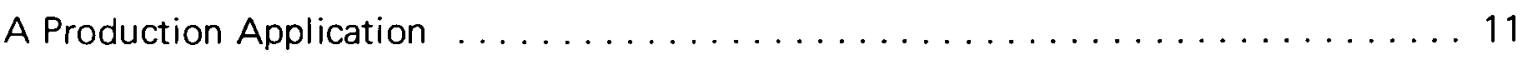

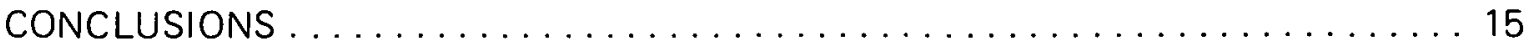

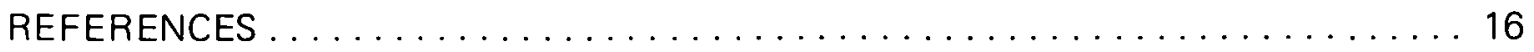

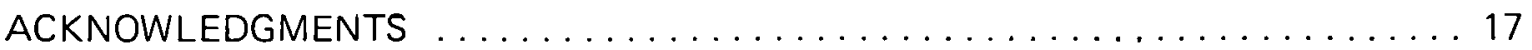

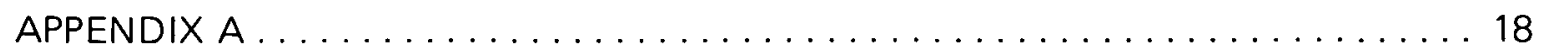

Operating Procedure for Data Collection $\ldots \ldots \ldots \ldots \ldots \ldots \ldots \ldots \ldots \ldots \ldots$

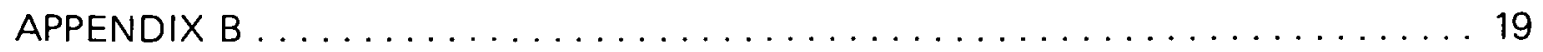

Operating Procedure for Control . . . . . . . . . . . . . . . . . . 19

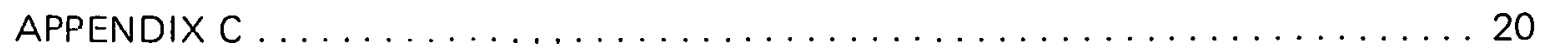

A Program for Providing Ram Feed and Voltage Control to Prevent Overculrent . . . . 20 


\section{SUMMARY}

A computer-based system for collecting data and for controlling electrochemical-machining (ECM) operations has been developed. The system can monitor a large number of process parameters and can send control signals to as many as 16 machines. The objectives are to develop a better understanding of basic process-parameter interactions through data collection and analyses and to use this knowledge to improve tolerances and efficiency through real-time control of the major independent parameters. Real-time control will be established by developing algorithms for particular applications. One such algorithm has been developed that allows the ECM of large-surface-area parts with the use of a relatively low-current power supply. This is achieved by controlling the voltage and the ram feed rate to maintain a constant machining gap between the tool (cathode) and the workpiece (anode). 


\section{INTRODUCTION}

Electrochemical machining can best be described as the reverse process of electroplating. The workpiece, from which material is removed, is made the anode in an electrolytic cell; and the tool, which is essentially the inverse image of the desired part shape, is made the cathode. Material is removed from the workpiece by passing a direct current through an electrolyte in the gap between the two electrodes. The electrolyte is pumped through the gap at a typical pressure of 100 to 200 psig. According to Faraday's laws of electrolysis, 1 the amount of material removed is proportional to the current transmitted. Workpiece material is essentially dissolved in the electrolyte and carried away. As the shaped tool moves toward the workpiece with an electric potential between the two electrodes and electrolyte flowing in the gap, the workpiece assumes the shape of the cathode. Allowances for electrolyte flow characteristics and overcuts are designed into the ECM cathode.

The ECM method is used extensively at the Oak Ridge $Y-12$ Plant (a) to produce parts from difficult-to-machine : electrically conductive materials and/or to produce parts having complex shapes. Some of the major advantages of the process are: (1) material removal rate is virtually independent of the physical properties of the metal, (2) surface finish is usually good with no mechanical stresses or burrs, (3) tool wear is minimal, and (4) many hours of conventional machining can be replaced with one quick ECM operation. The method does have some drawbacks, however, such as high capital and tooling costs, considerable consumption of electrical power, and difficulties in achieving close tolerances. The high cost of ECM equipment and the expense of tooling development are not likely to decline. However, energy efficiency can be realized by operating under optimum conditions, and tolerances can be improved by maintaining better process control.

An ECM automation effort is underway in the $\mathrm{Y}-12$ Plant to strengthen the basic knowledge about the process through instrumentation, data collection, and analyses in order to improve tolerances and productivity by providing control of the major process parameters. Goals of the effort are to improve the quality of the parts presently produced by ECM and to make ECM competitive for jobs that are normally fabricated by conventional methods.

(a) Operated by the Union Carbide Corporation's Nuclear Division for the Department of Energy. 


\section{IN-PROCESS DATA COLLECTION AND CONTROL}

\section{INTRODUCTION}

In-process data collection and control are accomplished by monitoring critical parameters at selected time intervals during operation, making decisions based on the readings, and correcting the independent variables accordingly. A necessary starting point is the identification of the critical parameters. Since ECM is not a new and revolutionary method for material removal, significant contributions have been made to the understanding of the process. Mathematical models and theoretical algorithms that define process interaction have been developed. Flow charts have been published that document the interdependence of process variables. 2 This basic process information provides a starting point for an ECM in-process data collection and control program.

\section{DESIGN CONSIDERATIONS}

The ECM data collection and control program was undertaken as a long-range effort. The objective is to provide a general capability for measuring and controlling ECM parameters and for developing, as required, the control programs necessary for particular applications. A.Digital Equipment Corporation (b) (DEC) PDP-11/34 computer with $32 \mathrm{k}$ words of core memory and 7.5 megawords of disk storage was procured; and an add-on interfacing scheme, illustrated in Figure 1, was designed. The interface uses asynchronous

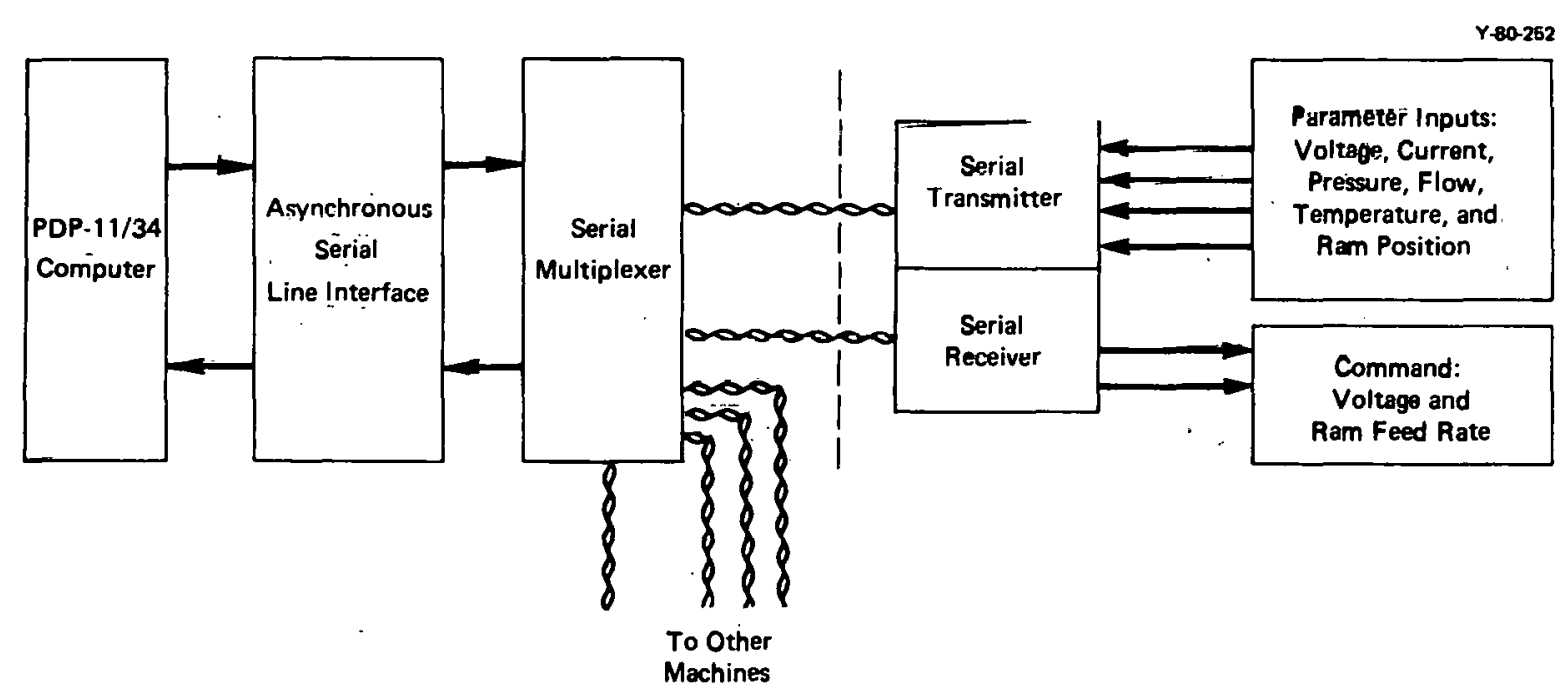

Figure 1. THE INTERFACING SCHEME FOR THE ELECTROCHEMICAL-MACHINING AUTOMATION PROGRAM.

(b) Digital Equipment Corporation, Maynard, Massachusetts. 
data-transmission links with Analog Devices(c) Serdex modules in a 20-mA-current loop mode. Parameter data in the American Standard Code for Information Interchange (ASCII) form is transmitted from sensors on the ECM machine to the computer, and command signals are fed from the computer to the machine for control.

For data collection, the information flow is as follows: the serial multiplexer channel for data collection from a particular machine is selected by an ASCII output, \#n ( $\mathrm{n}$ is the channel number). A signal is then sent to the serial transmitter, which selects the parameter to be read. The computer requests input; four decades of binary-coded-decimal (BCD) data are transmitted through the multiplexer and DL-11 (DEC's asynchronous serial interface); and the data for that particular parameter is stored. For automatic control, three decades of $B C D$ data are transmitted from the computer, through the DL-11 and multiplexer, to a serial receiver. If the parameter being modified accepts digital input, the receiver output serves as the command to produce the proper corrective action. If not, the digital command signal serves as the input to a digital-to-analog convertor where output is gated to produce the proper response. The serial multiplexer thus allows one computer to collect data from and/or control several machines at one time. The basic interfacing scheme must be duplicated for each of these machines.

\section{DATA COLLECTION SOFTWARE}

The RSX-11M, real-time, multitasking software system provided by DEC was chosen to facilitate communication from the central computer to the terminals of the various machines. This communication can take any of three forms: (1) data collection and presentation; (2) data collection, analysis, and control; or (3) single-parameter monitoring and control. The first form is applicable for process monitoring and basic parameterinteraction studies and for providing fabrication history of production parts. The second form is appropriate for process monitoring and control when an out-of-tolerance parameter requires correction, though not immediately. The third form of communication will be discussed at length in an example and is appropriate when immediate action is required wherever a parameter is out of specification.

A "master-slave" scheme was implemented to provide data collection and noncritical control. As illustrated in Figure 2, the master program accepts input and queues the slave programs as appropriate. The input commands accepted by the master program are: (1) the machine to monitor and/or control, (2). the number of data scans required, (3) the time interval between scans, and (4) the part number. The master program calls the slave programs through a time-based RUN directive, which is part of the operating system. An example of a data-collection run is shown in Figure 3.

For applications that require immediate response to out of tolerance conditions, the master-slave scheme is not appropriate. These control programs continually monitor the critical parameter(s) and take immediate action to eliminate parameter deviations.

(c) Analog Devices, Inc; Norwood, Massachusetts. 


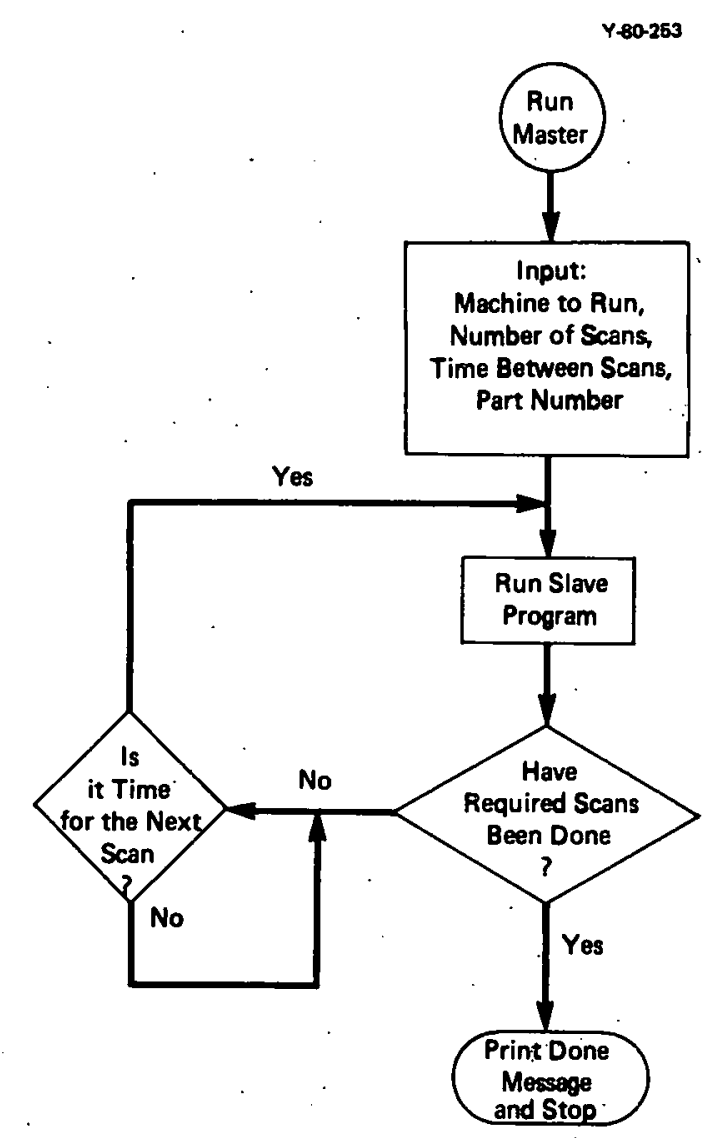

Figure 2. THE OPERATION OF THE MASTERSLAVE SOFTWARE SYSTEM FOR ELECTROCHEMICAL-MACHINING DATA COLLECTION AND CONTROL.
RUN MASTER

DATA WILL BE TAKEN EVERY 30 SECONDS. HOW MANY SCANS? $\underline{22}$ WHICH MACHINE? ECM

PART NUMBER (XXXX-XX-XXXX)? 7849-87-6143

THIS IS THE ECM DATA COLLECTION PROGRAM
TIME: 8:43:15 $5 / 14 / 78$

TIME: $8: 43: 15 \quad 5 / 14 / 78$
PART NUMBER: $7849-87-6143$

THE RESULTS OF THE LAST SCAN ARE:

MACHINING VOLTAGE

MACHINING CURRENT

ELECTROLYTE INJECTION PRESSURE

ELECTROLYTE FLOW RATE

RAM POSITION

019.7 VOLTS

2374 AMPS

0127 PSIG

0059 GPM

0014 MILS

THIS IS THE ECM DATA COLLECTION PROGRAM

TIME: 8:43:45

$5 / 14 / 79$

PART NUMBER: $7849-87-6143$

THE RESULTS OF THE LAST SCAN ARE:

MACHINING VOLTAGE

MACHINING CURRENT

ELECTROLYTE INJECTION PRESSURE

ELECTROLYTE FLOW RATE

RAM POSITION

019.4 VOLTS

3106 AMPS

0127 PSIG

0060 GPM

0034 MILS

Figure 3. A PRINTOUT OF A TYPICAL DATA-COLLECTION RUN FROM THE 10,000-A, VERTICAL, ELECTROCHEMICAL-

MACHINING MACHINE. (Underlined characters are operator inputs.) 


\section{IMPLEMENTATION}

The ECM automation effort is a multiphase program. When complete, the central computer will collect data from and/or control two Anocut(d) 10,000-A, vertical underdriven machines; an Anocut, 20,000-A, horizontal machine; a Chem Form (e) 2500-A, vertical machine; an electrochemical contour grinder (ECCG) built at the $\mathrm{Y}-12$ Plant and the electrolyte-handling facilities for all operations. To date, two machines have been connected to the computer. These are a 10,000-A, vertical, underdriven machine shown in Figure 4 and an ECCG machine shown in Figure 5.

The vertical ECM machine was instrumented and interfaced for data collection and control. Digital panel meters with BCD outputs were included to monitor machining voltage and current; the necessary circuitry was developed to record ram travel from a reference position; and transducers and appropriate readouts were installed to monitor electrolyte pressure, flow rate, and temperature. Necessary modifications were also made to the vertical machine to provide automatic control of ram feed rate and machining voltage. On this

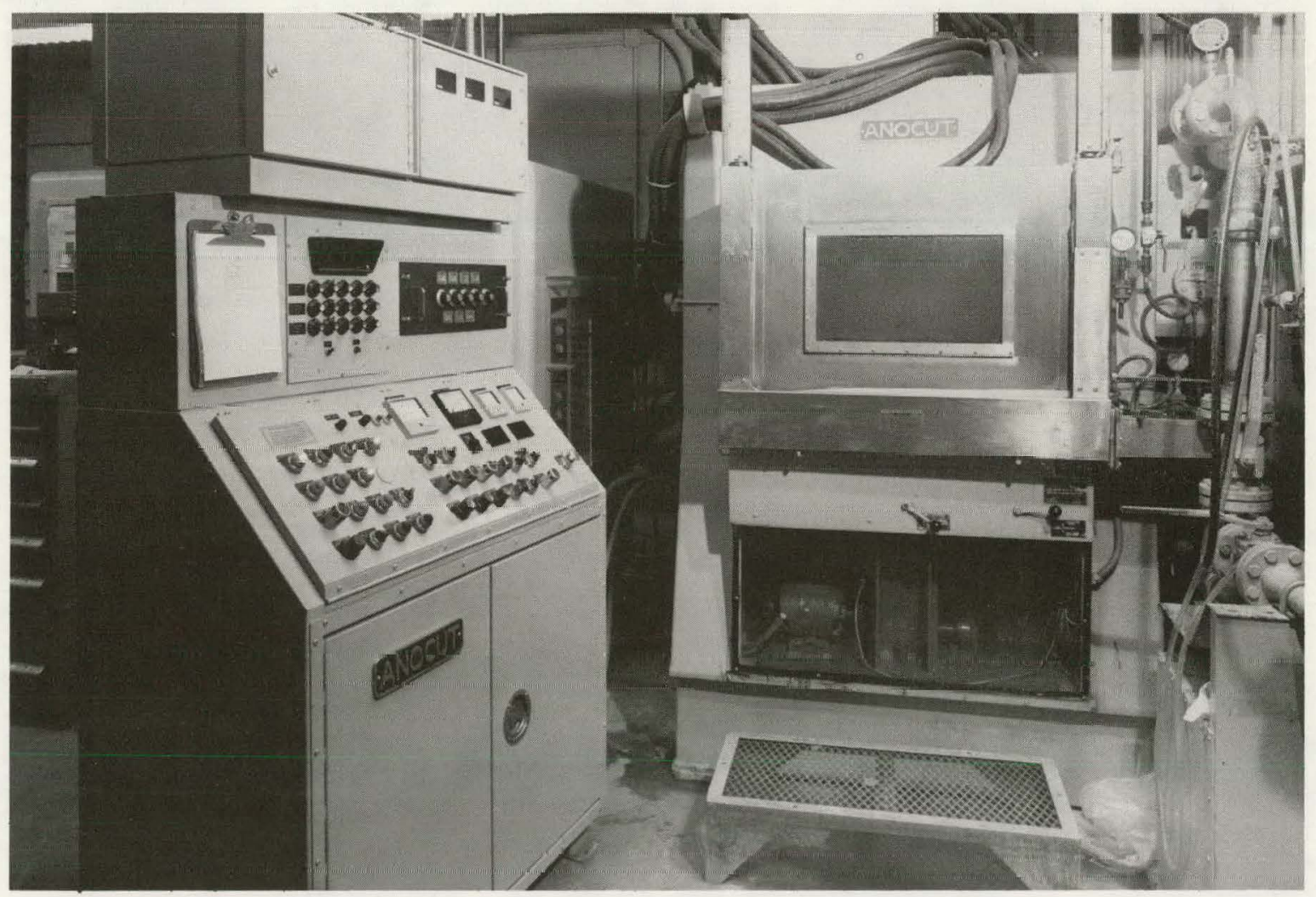

182061

Figure 4. THE ANOCUT, 10,000-A, VERTICAL, UNDERDRIVEN, ELECTROCHEMICAL-MACHINING MACHINE. (The cabinet on top of the control console houses the data-collection-and-control electronics.)

(d) Anocut, Inc, Elk Grove Village, Illinois.

(e) Chem Form, Pompano Beach, Florida. 


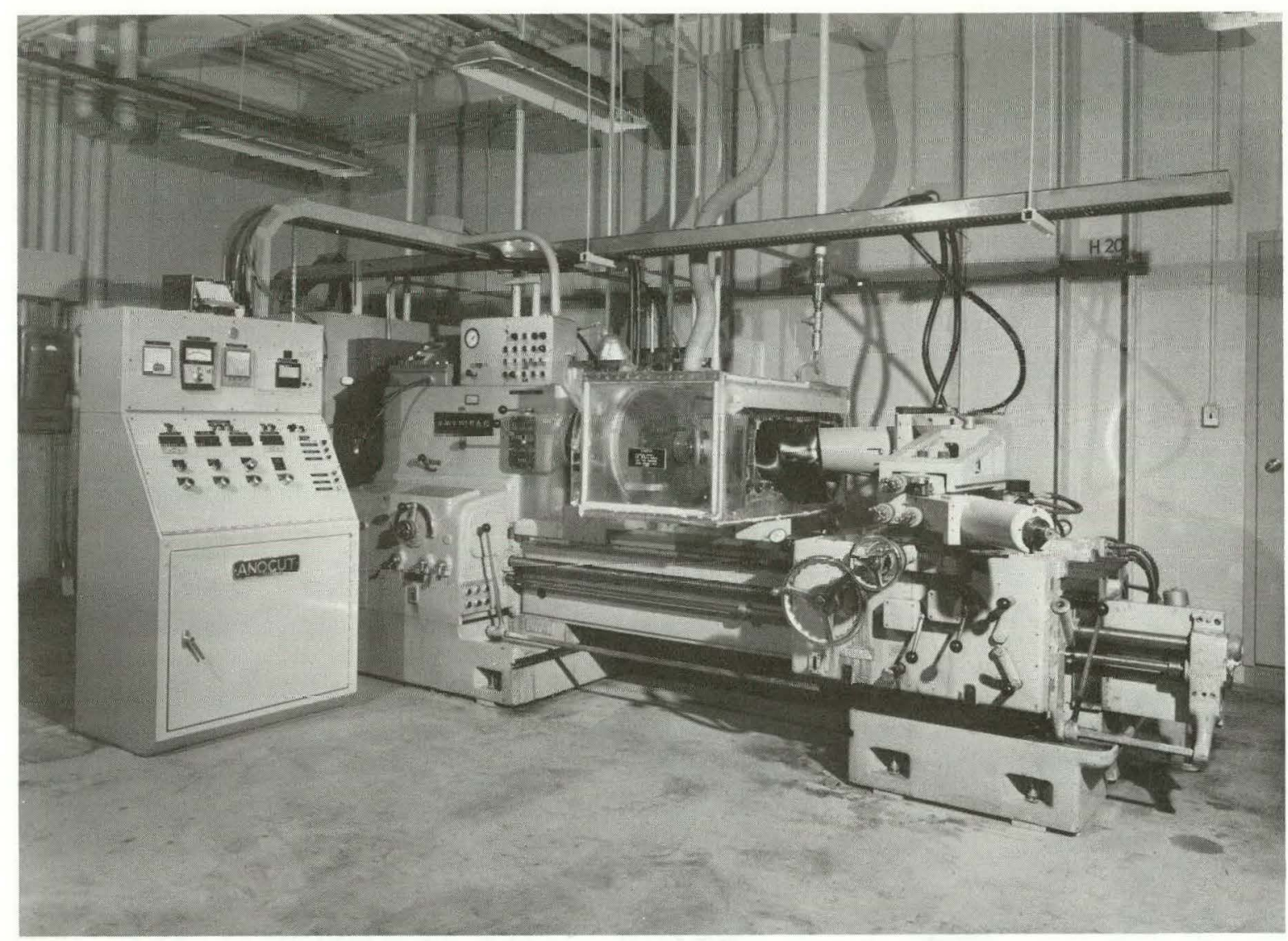

181941

Figure 5. AN ELECTROCHEMICAL CONTOUR-GRINDING MACHINE WHICH IS INSTRUMENTED FOR AUTOMATED DATA COLLECTION.

machıne, the ram speed is normally controlled by a Graham drive system with a manual adjustment. This fealure was replaced with a computer-controlled stepping-motor drive system. Pushbuttons were also added to provide a "jog" capability for setting initial speed. The 10,000-A power supply is a saturable reactor type, and the output voltage is determined by a DC level applied to a differential amplifier. Voltage control is provided by a voltage dividing potentiometer which changes the amplifier input. For automatic control, the digital to analog convertor drives an amplifier whose output replaces the potentiometer.

The ECCG machine was interfaced for data collection only. The parameters monitored include: machining voltage and current; current and rotational speed of the grinder-spindle motor; and electrolyte flow, pressure and temperature.

\section{IN-PROCESS CONTROL CONCEPT}

Optimum ECM process performance is, in most cases, the removal of material at maximum practical rates to produce parts that are in tolerance. Maintenance of tight tolerance requires the precise repetition of the process procedure with no deviation in critical process parameters. Therefore, tolerance improvement can be realized by maintaining a tight control of these parameters. 
During an ECM operation, as the space between the ram and the workpiece decreases, the resistance to current flow also decreases. Current, therefore, increases until it is sufficient to remove material at exactly the same rate as the ram advance. Unless conditions change, the process will continue in this equilibrium condition. In this operating mode, the distanice between the tool (cathode) and the workpeice (anode) is defined as the equilibrium interelectrode gap. The accuracy of the final workpiece shape depends on the constancy of the gap during the operation, and tolerance requirements dictate the maintenance of the same gap for all parts produced. Fortunately, optimum surface finishes and tolerance control result from relatively high material removal rates; and the material removal rate is proportional to the current density which is the current between the electrodes per unit area. Therefore, conditions for optimum machining require maximum reasonable current density (determined by voltage and feed rate) and the maintenance of a constant interelectrode gap for a given cathode configuration. The maximum current density is limited by the part configuration, the current capability of the power supply, and the electrolyte limit, which is the ability of the electrolyte to carry away metallic particles,' to remove the hydrogen gas released, and to dissipate the heat generated. 3 The electrolyte limit is a function of solution type, concentration, flow, temperature, and pressure.

In general, in-process control of ECM allows maximum practicable material removal, which is constantly maintained and repeatable through successive operations. If the workpieces and cathodes were of simple geometry, optimum conditions could be realized by maintaining a constant voltage and feed rate and monitoring the electrolyte parameters for changes. Any changes in the electrolyte would signal for corrective action. However, most candidate parts are nonplanar, presenting a great variety of geometric configurations and surface areas. Therefore, since current is directly related to both ram feed rate and voltage, the maintenance of constant current density requires automatic control of these parameters. Such control allows fast feed rates and high voltages for machining small-surface areas and for programmed reduction of these parameters as the area increases.

\section{APRODUCTION APPLICATION}

The goal of ECM control is to extend the range of application through better tolerance control and more efficient machine utilization. A family of parts to be produced in the $Y-12$ Plant are intricately shaped and have surface areas as large as $120 \mathrm{in}^{2}$. These parts consist of both straight and tapered walls on the inner contour and large-area bottoms. Normal operating conditions require current densities of approximately $1,000-\mathrm{A} / \mathrm{in}^{2}$. Since the only machine available has a current capability of $10,000 \mathrm{~A}$, alternative conditions for machining are required. Since current is directly related to both vol tage and ram speed, the parts could be produced by operating at low voltage and minimum ram speed for the enlire cut. However, the total travel distance is as much as 4 in and a ram speed as low as 0.0005 in/min is required. This operation would require about 13 hours per part and, therefore, does not represent efficient use of the machine. Since considerable power is consumed in maintaining electrolyte flow and providing machine control, this approach is also energy inefficient. 
In-process control of machining voltage and ram feed rate (based on current) provide a solution to these problems. Maximum material can be removed at all times by operating at high voltage and fast feed rate as the side walls are machined and by reducing these parameters when high current indicates the large-area bottom is approaching. This method was chosen for this endeavor because it provides cost effectiveness and energy efficiency when compared with conventional alternatives.

The production of a predictable part (this example or any other) with acceptable properties such as surface finish requires that a uniform equilibrium gap be maintained for the entire operation. Since current and gap are directly related to both ram feed rate and voltage, a simple mathematical relationship can be established for gap, voltage and feed rate if all other parameters are held constant. Therefore, this part can be produced with a constant interelectrode gap by selecting voltages and feed rates according to an empirical algorithm. To develop the necessary algorithm (for this material) for a standard set of electrolyte conditions, $2.54-\mathrm{cm}$-diameter holes were machined by ECM in $1.27-\mathrm{cm}$-thick plates at different voltages and feed rates. All other parameters were held constant, and the gaps were determined. The ram was advanced into the workpiece $0.64 \mathrm{~cm}$, and the actual depth of the cut was measured. The frontal overcut (gap) is simply the measured depth minus 0.64 $\mathrm{cm}$. To determine side overcut, the diameter of the hole was measured and compared with the diameter of the cathode. Since the cathode is $2.54 \mathrm{~cm}$ in diameter, the side overcut is the hole diameter minus $2.54 \mathrm{~cm}$. Families of constant gap curves for voltages and feed rates were defined by the data as shown in Figures 6 and 7. Equations were derived that define the algorithm for the family of curves. One form of the equation for frontal gap is:

$$
Y_{f}=\frac{V-0.085398 a-5.01}{0.0024441 a+0.0025048}
$$

A form of the equation for the side gap is:

$$
Y_{S}=\frac{V-0.51947 a+4.3612}{0.00033603 a+0.009761}
$$

The symbols for both equations are:

$$
\begin{aligned}
& Y \text { - gap in } \mu \mathrm{m}, \\
& V \text { - machining voltage in volts, } \\
& \text { a - feed rate in } \mu \mathrm{m} / \mathrm{s} \text {. }
\end{aligned}
$$

Since the part has depth and both side and frontal machining occurs, both gaps must be constant as feed rates and voltages change. This requires that the slope of the voltage and feed-rate curves (Figures 6 and 7) be the same for both gaps. A frontal gap of $299 \mu \mathrm{m}$ and a side gap of $883 \mu \mathrm{m}$ satisfies this slope requirement, and the performance of the process with 


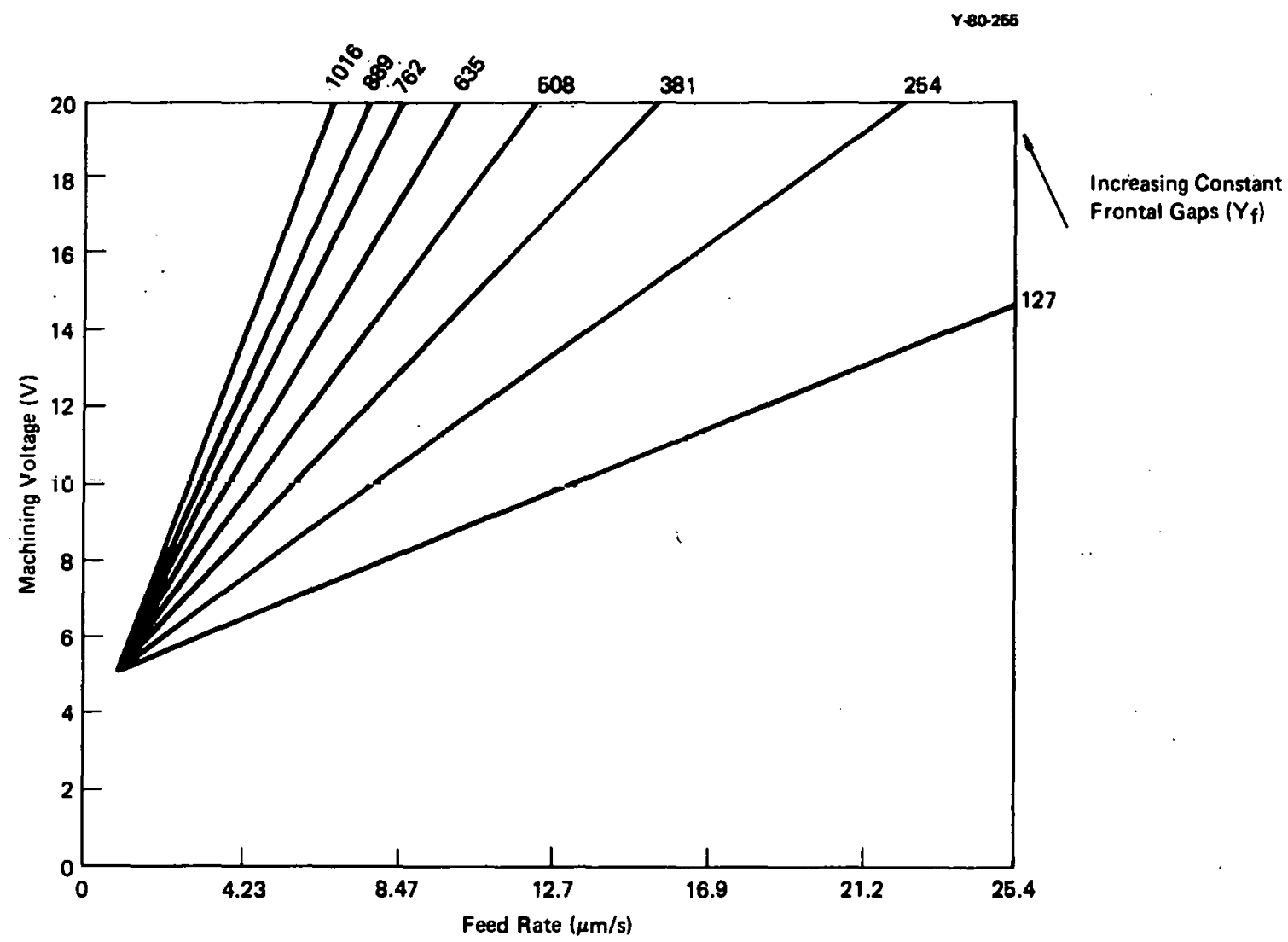

Figure 6. FAMILY OF CURVES OF VOLTAGE VERSUS FEED RATES AT CONSTANT FRONTAL GAPS FOR ELECTROCHEMICAL-MACHINING TESTS. (Shown in $\mu$ in.)

these gaps is acceptable. By substituting these variables into the Equations (1) and (2), a single equation relating voltage and feed rate results:

$$
V=0.816 a+4.26
$$

By using the in-process control system to implement this equation, constant gap machining can be performed with voltages and feed rates selected to keep the current below the power-supply limit of 10,000 A, thereby making possible the production of these parts.

In this application, control is provided only to prevent overcurrent; and no attempt at full automation is intended. The machinist installs the part on the machine, sets the initial conditions, and starts the process. The computer monitors the current until a 10,000-A level is reached. The voltage is then reduced by $0.1 \mathrm{~V}$, a new feed rate is calculated and commanded, and machining current is again read. Parameter printouts are provided, if desired, at selected time intervals. When the predetermined shutdown position is reached, the machinist removes the part and terminates the control program. A printout of a typical control run is shown in. Figure 8. 


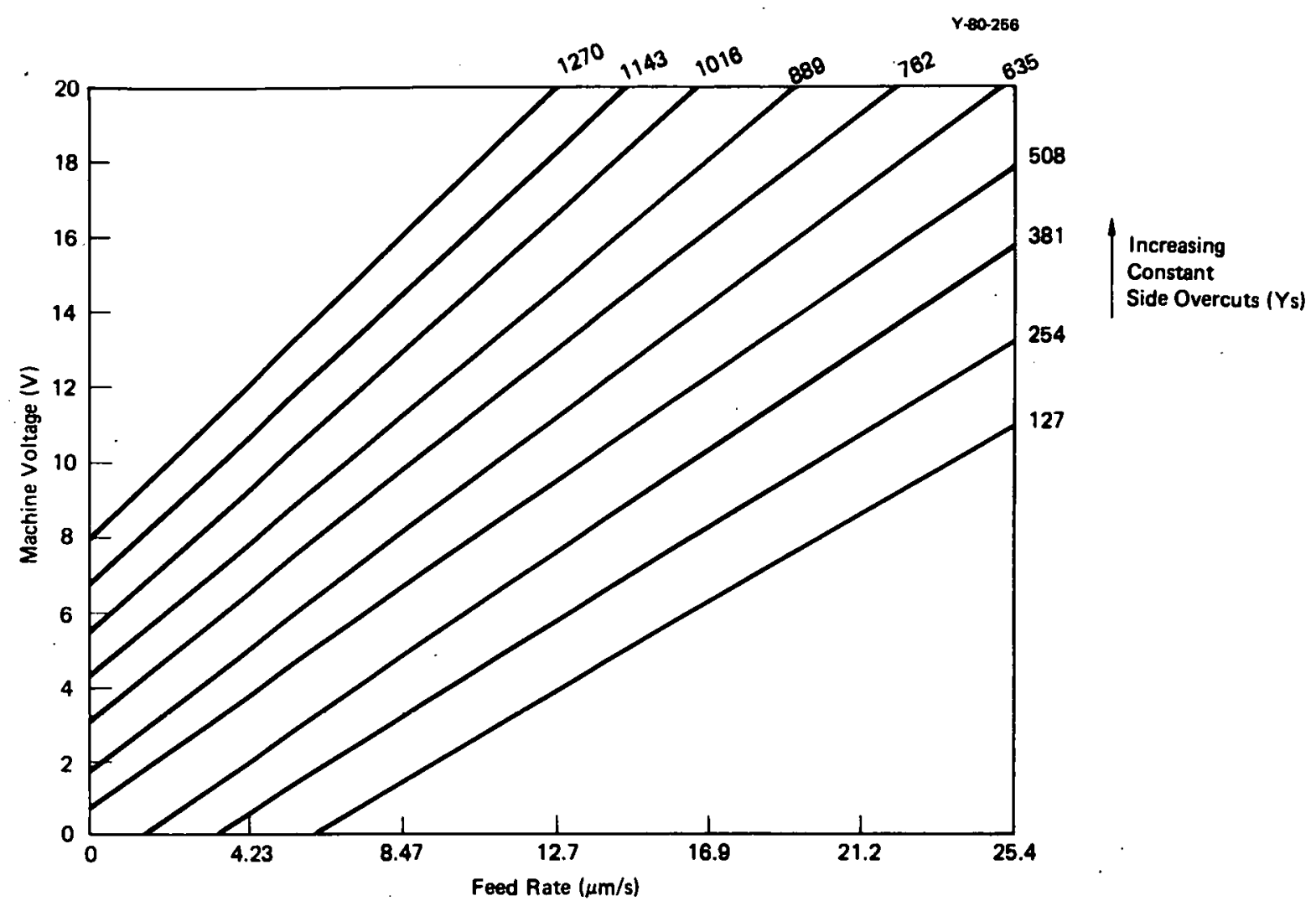

Figure 7. FAMILY OF CURVES OF VOLTAGE VERSUS FEED RATES AT CONSTANT SIDE OVERCUTS FOR ELECTROCHEMICAL-MACHINING TESTS. (Shown in $\mu$ in.)

This algorithm represents one of many possible applications for ECM rontrnl For further applications, appropriate algorithms can be implemented with the same hardware. The control program is written in machine language and is divided into two sections. The main program calls calculation subroutines which are easily changed for new equations.

In this application many things are taken for granted, such as constancy of electrolyte properties such as conductivity and flow. In reality, this is not a valid assumption; and future programs will address such problems.
RUN CONTROL.

IS IHE MACHINE READY? YES ) OPERATION UNDERWAY

CURRENT HAS CROSSED 10,000 AMPS - BEGIN CONTROL. CURRENT

VOLTAGE COMMAND $\quad 17.4$ VOLTS

SPEED COMMAND $\quad 16.10 \mu \mathrm{m} / \mathrm{min}$

CURRENT

$\begin{array}{lr}\text { VOLTAGE COMMAND } & 17.3 \mathrm{VOLTS} \\ \text { SPEED COMMAND } & 15.86 \mu \mathrm{m} / \mathrm{min}\end{array}$

CURRENT

VOLTAGE COMMAND 10084 AMPS

$15.85 \mu \mathrm{rit} / \mathrm{min}$

$\begin{array}{lr}\text { CURRENT } & 10102 \text { AMPS } \\ \text { VOLTAGE COMMAND. } & 7.6 \text { VOLTS } \\ \text { SPEED COMMAND } & 4.09 \mu \mathrm{m} / \mathrm{min}\end{array}$

Figure 8 AN EXAMPLE OF A CONTROLLED ELECTRO. CHEMICAL-MACHINING OPERATION. THE VOLTAGE AND RAM SPEED ARE REDUCED ACCORDING TO AN ALGORITHM TO KEEP CURRENT NEAR 10,000A. 


\section{CONCLUSIONS}

An ECM in-process data collection and control program is a long-range endeavor with exciting possibilities. The ability to control the process by manipulating just a limited number of process parameters allows the efficient machining of tight-tolerance parts. As the program çontinues, the goal is to broaden the scope of practicality for ECM by making ECM economically competitive for jobs previously committed to more conventional fabrication methods. 


\section{REFERENCES}

1. Electrochemical Machining, A. E. DeBarr and D. A. Oliver, Eds. (American Elsevier, New York, 1968).

2. "Electro Chemical Metal Removal Processes," Non-Traditional Machining Processes, R. K. Sṕringborn, Ed. (American Society of Tool and Manufacturing Engineers, Dearborn, Mich., 1967), p. 44.

3. ECM, ECD, ECG Simplified, Chem Form Corporation, Pompano Beach, Fla. 


\section{ACKNOWLEDGMENTS}

An endeavor of this scope cannot be accomplished without a cooperative effort. W. Q. Adams was associated with and responsible for many of the accomplishments described. J. D. Hensley and J. T. Fisher provided the necessary mechanical expertise, and $\mathrm{Mr}$. Fisher conducted the tests and developed the control algorithm. They are members of the Fabrication Systems Development Department. An operating staff headed by R. L. Williams of the Fabrication Division was most cooperative in tolerating interruptions and in assisting in necessary tests. 


\section{APPENDIX A}

\section{OPERATING PROCEDURE FOR DATA COLLECTION}

If the computer is OFF, the following procedure must be followed to prepare it for operation:

Start-up

1. Turn the power switch to ON.

2. Simultaneously, press CONTROL and BOOT.

3. Respond to the $\$$ printed on the terminal with DK ) ( 2 means return).

4. The system will then load the necessary programs and ask for time and date. Respond in the form:

HOUR:MINUTE:SECOND TAB MONTH/DAY/YEAR

The hour must be entered on a 24-hour clock.

5. The terminal will print EOF>.

The RSXIIM operating system is now ready to operate. Proceed to operate. After the system is running, the following steps are necessary for data collection:

Operate

When the computer requests input, a front arrow $(>)$ is typed; the underlined characters are operator responses.

1. To install the proper programs, input as follows:

$$
\frac{\frac{\geq \text { INS MASTG ) }}{\text { INS ECM ? }}}{\geq \text { INS ECG ) }}
$$

2. If the printout is desired at the auxiliary terminal, input:

$$
>\text { REA ECM_5_ TT2: . }
$$

3. The system will only collect data if power is $\mathrm{ON}$ at the machine. To run the data-collection programs, type:

\section{$>$ RUN MASTG}

4. Answer the questions as follows:

Which machine do you want to run? $\underline{n}$ ( $\mathrm{n}$ is 1 for the vertical ECM and 2 for the ECCG).

How many scans? $X X$ (must be two numbers).

What is the part number? $x x x x-x x-x x x x$.

5. The system will collect and present data every 30 seconds for the required number of scans. 


\section{APPENDIX B}

\section{OPERATING PROCEDURE FOR CONTROL}

The start-up procedure described in Appendix A must be followed before any program can be run.

1. The operator must install the part on the machine, set the predetermined shutdown position, and set the initial ram velocity. He then starts the electrolyte pump, turns on the machining power, and flips the power control switch to COMPUTER.

2. On the terminal at the machine type

\section{$\geq$ RUN CONT ?}

3. In response to IS THE MACHINE READY?, type ? .

4. Both the control system and the ECM machine are now ready to operate. The control system sets the required voltage and monitors the ram position until a number other than 0000 is read. This indicates that the operator has initiated motion and the process is underway.

5. The control system now continuously monitors machining current until 10,000 A are reached. When this occurs, the message CURRENT HAS CROSSED 10,000 A - BEGIN CONTROL will be printed; and a new voltage and feed rate will be commanded. The commands will be presented at the terminal.

6. This process continues until the predetermined shutdown position is reached and the machine shuts down. The operator then removes the part.

7. Type CONTROL Z to terminate the control program. 
APPENDIX C

\section{A PROGRAM FOR PROVIDING RAM FEED AND VOLTAGE CONTROL TO PREVENT OVERCURRENT}

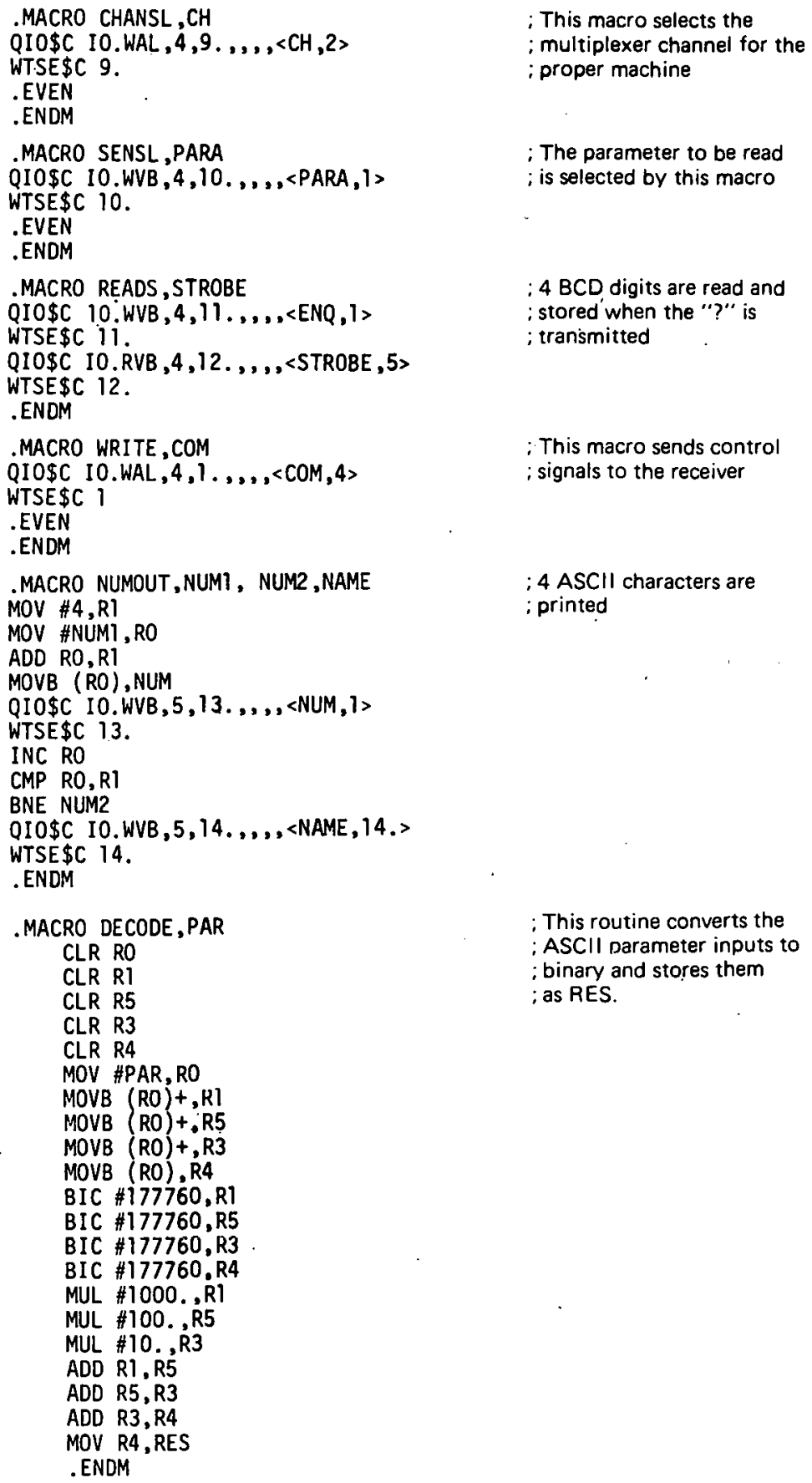

; The parameter to be read ; is selected by this macro

: $4 \mathrm{BCD}$ digits are read and istored when the "?" is

; transmitted

: This macro sends control ; signals to the receiver

; 4 ASCII characters are iprinted

: This routine converts the : ASCII parameter inputs to ; binary and stores them ; as RES 
START: .MCALL QIO\$C,MRKT\$C,WTSE\$C, CHANSL, SENSL, WRITE, EXIT \$S, READS, DECODE, NUMOUT, CLEF \$C,WT LO\$C

\begin{tabular}{|c|c|}
\hline $\begin{array}{l}\text { MOV \#600, , INIT } \\
\text { CHANSL Ni } \\
\text { SENSL AS } \\
\text { SENSL EQ } \\
\text { WRITE VOLTS } \\
\text { SENSL DO } \\
\text { MRKT \$C } 2,1,2 \\
\text { WTSE \$C } 2 \\
\text { SENSL QU } \\
\text { SENSL AS }\end{array}$ & $\begin{array}{l}\text {; INITIAL FEED RATE } \\
; \text { CHANNEL } 1 \text { - TRANSMIT (1005) } \\
; \text { RESET } \\
\text {; SELECT VOLTAGE } \\
\text {; COMMAND INITIAL VOLTAGE } \\
\text {; WAIT } 2 \text { TICKS } \\
; \text { STROBE VOLTAGE } \\
\text {; RESET }\end{array}$ \\
\hline
\end{tabular}

;CHECKK POSITION AND PRINT INITIAL CONDITIÓNS

ZERO: SENSL RESET

; RESET

SENSL RAM

READS POS $\quad$ : READ POSITION OF RAM

DECODE POS ; CONVERT ASCII TO BINARY

CLR RT

MOV RES, RI ; PUT RESULT IN RI

CMP RI, \#0 ; IS POSITION 0 ?

BEQ ZERO ; YES - READ AGAIN

QIO\$C 10.WVB , 5,i, , , <BEGIN, VNAME-BEGIN $>$

; LAST CHECK FOR READY; NO - RAM HAS MOVED FROM ZERO

QIO\$C IO.RVB, $5,4, \ldots,<G 0,1>\quad ; G O$

WTSE $\$ C 4$

SENSL RESET

;RUN HAS STARTED:

WATCH CURRENT FOR 10,000 AMPS

CONTROL :

SENSL RESET.

SENSL CURR

READS CURRI

SENSL RESET

DECODE' CURRI

CLR R1

MOV RES, RI

SUB \#1000., R1

BMI CONTROL

; SELECT 1003

QIO\$C IO.WVB

WTSE\$C 2

NUMOUT CURR1, CURR2, CNAME

;CURRENT HAS CROSSED 10,000 AMPS ; START CONTROL

; READ CURRENT

CLR RO

MOV \#0,R1

MOV \#O,R2 .

MOV \#O,R3

SENSL RESET

; CONVERT ASCII CURRENT TO BINARY

OOPS: MOV RI,R3

; STORE RESULT IN R]

; IS CURRENT $>10,000$ AMPS?

; NO - CHECK AGAIN

SENSL VOLT

READS VOLTI

DECODE VOLTI

CLR RO

MUV KLS, Ki

SUB \#10.,RI

MOV RT, R3

SUB \#1800., R3

BMI OOPS

MOV \#1795. , RI

SUB \#1450. R3

BMI VLESS

CLR R2

CLR R4

CLR R5

MOV \#350., R4

SUB R3, R4

MOV R4, R3

MUL \#4,R3

DIV $\# 10 .$, R2

ADD R2, RI

JMP UPVOLT

; READ VOLTAGE

; CONVERT VOLTAGE TO BINARY

; STORE VOLTAGL IN RI

; DECREASE VOLTAGE BY 0.01

; IS VOLTAGE > 18.0?

; NO: PROCEED

; YES: SET COMMAND AT 17.95

; IS VOLTAGE > 14.5 ?

; NO: CHOOSE SECOND CURVE

; YES : VOLTAGE COMMAND $=\langle(350-[V \times 100-1450]) \times 4\rangle+V \times 100$

$\cdots$
; SUBTRACT 350 FROM VX100

; MULTIPLY RESULT BY 4

; DIVIDE BY 10

; ADD VX100 TO RESULT

; READY TO STORE NEW VOLTAGE COMMAND 


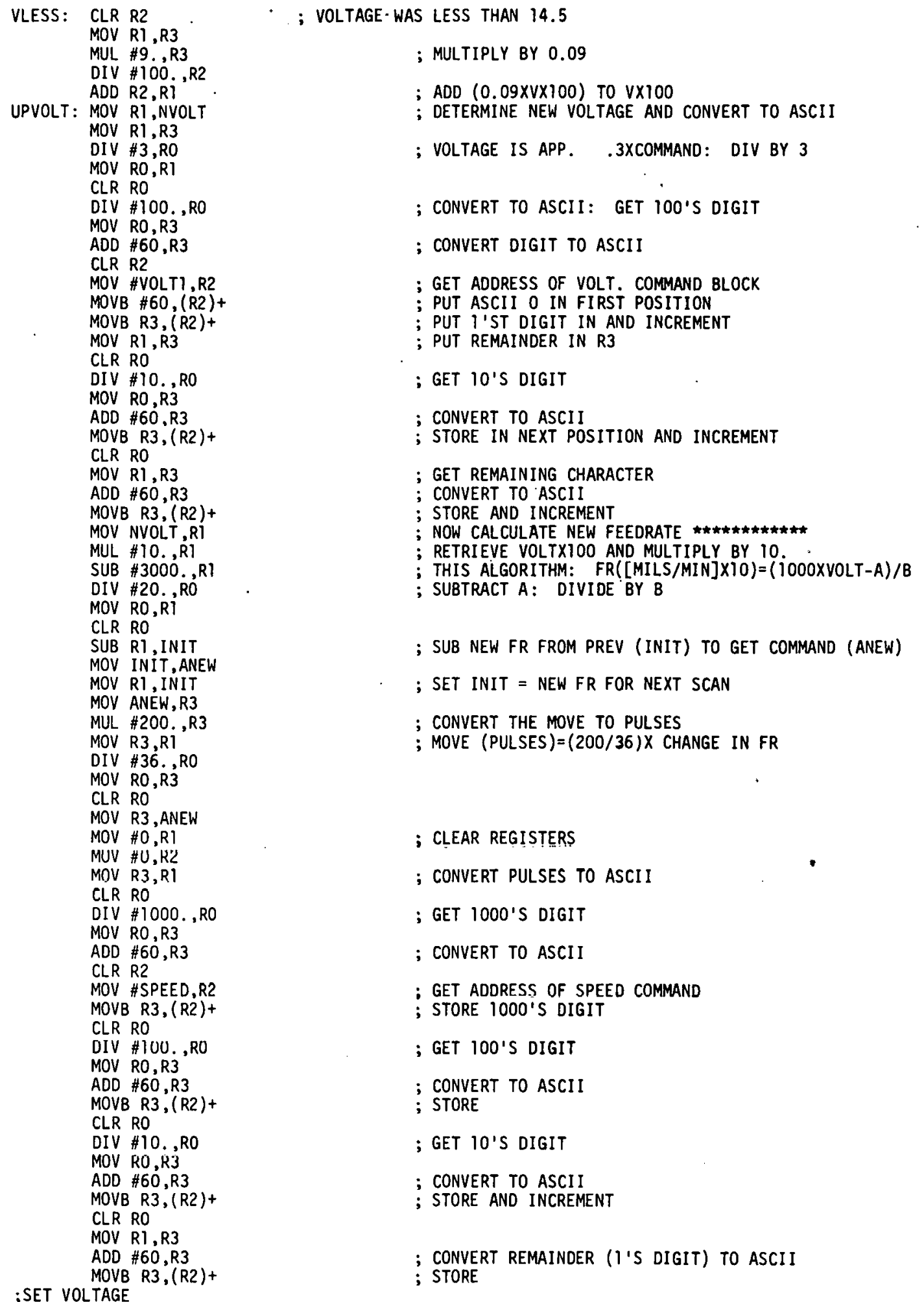

QIO\$C 10.WAL , $5,3, \ldots,,<$ VOLTAGE, CURREN'I - VOLTAGE >

; PRESENT VOLTAGE COMMAND

WTSE\$C 3

NUMOUT VOLTI, VOLT2, VNAME

QIO\$C 10.WAL ,5,4,,,, <RAMSP, VOLTAGE-RAMSP>

; PRESENT SPEED COMMAND 


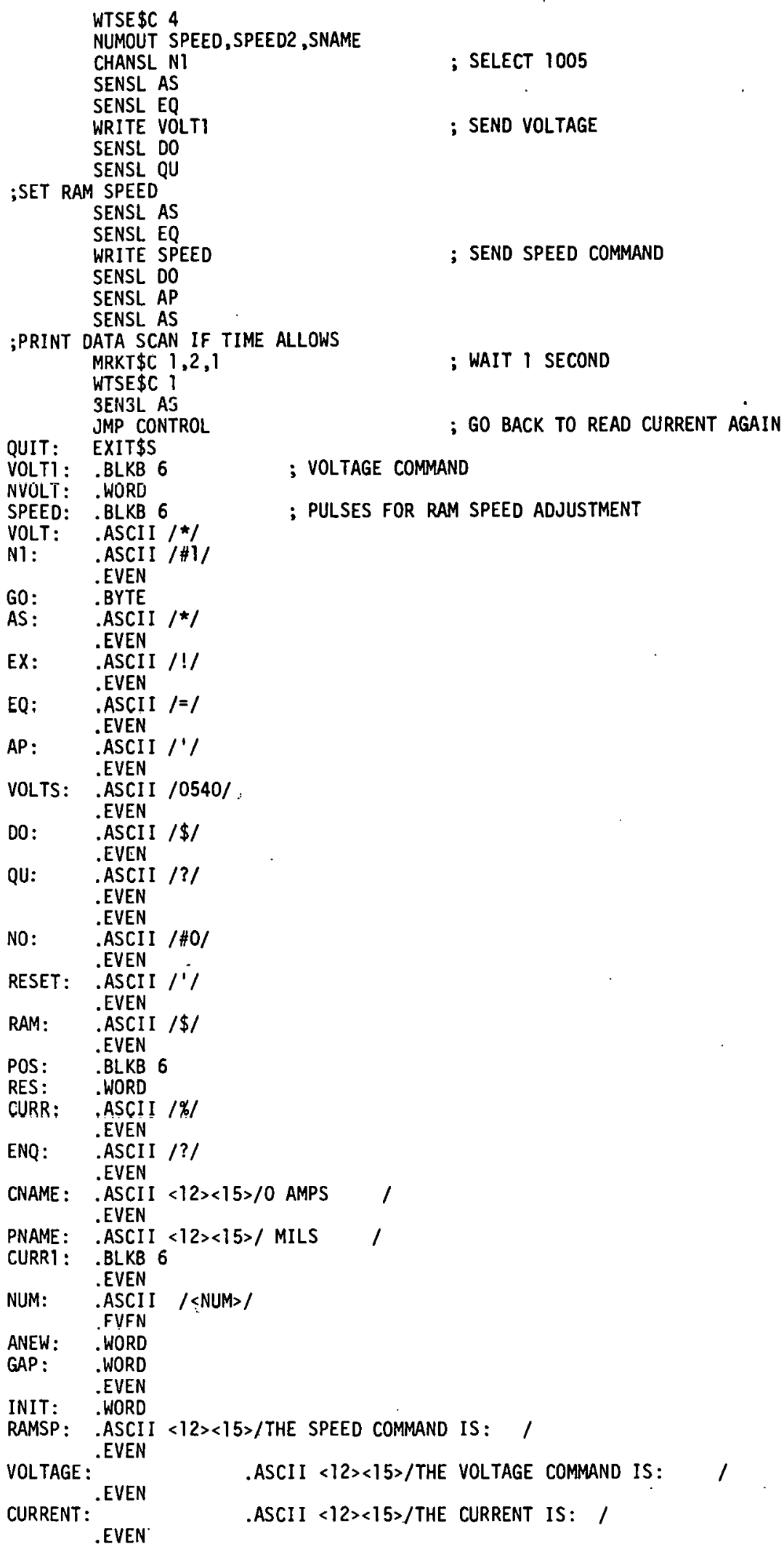

VOLT1: .BLKB 6 ; VOLTAGE COMMAND

; SELECT 1005

; SEND VOLTAGE

; SEND SPEED COMMAND

; WAIT 1 SECOND

; GO BACK TO READ CURRENT AGAIN

; PULSES FOR RAM SPEED ADJUSTMENT 
BEGIN: .ASCII $<12><15>/$ START CONTROL?/

VNAME: $\begin{aligned} & \text {. EVEN } \\ & \text {.ASCII } / \text {.3XVOLTS } /\end{aligned}$

SNAME : $\begin{aligned} & \text {.EVEN } \\ & \text {.ASCII } / \text { PULSES } /\end{aligned}$

END: $\quad$.ENEN START 


\section{Distribution}

Bendix-Kansas City

Cooper, W. G.

Department of Energy - Oak Ridge

Hickman, H. D.

Poteat, R. M.

Lawrence Livermore National Laboratory

Arnold, W. F.

Los Alamos Nationạl Scientific Laboratory

Hoyt, H. C.

Oak Ridge Gaseous Diffusion Plant

Armstrong, R. C.

Stief, S. S.

Wilcox, W. J., Jr.

Oak Ridge National Laboratory

Hopkins, C. C.

Oak Ridge $Y-12$ Plant

Adams, W. Q.

Arehart, T. A., Jr.

Bailey, H. L.

Bernander, N. K.

Bright, G. R.

Bullock IV, J.

Burditt, R. B.

Dodson, W. H./Gongin, J. M.

Dawson, D. O. (2)

Ferguson, J. E.

Fisher, J. T.

Foulk, D. L.

Fraser, R. J.

Hensley, J. D.

Hurst, J. S.

Jones, F. W.

Kahl, K. G.

Keith, A.

Kite, H. T.

Mason, D. L.

Mills, J. M., Jr.

Muenzer. W. A.

Murphy, S. M., Jr.

Neal, R. E. (15)
Passons, D. R.

Post, D.W.

Smith, H. F., Jr.

Smith, R. D.

Steele, R. S.

Steger, P. J.

Tewes, W. E.

Thompson, C. H.

Tilson, $F, V$.

Tunnell, H. A.

Waldrop, F. B.

Whitten, L. G., Jr.

Williams, R. L.

Wright, C. C.

$Y-12$ Central Files (master copy)

$Y-12$ Central Files (route copy)

$Y-12$ Central Files ( $Y-12 R C)$

$Y-12$ Central Files (5)

Paducah Gaseous Diffusion Plant

Bewley, H. D.

Rockwell International - Rocky Flats

Fuller, John

Quella, Jack

Sandia National Laboratories - Livermore

Spencer, W. J.

Union Carbide Corporation - New York

Tinsley, S. W.

In addition, this report is distributed in accordance with the Category UC-38, Engineering and Equipment, as given in the Standard Distribution for Unclassified Scientific and Technical Reports, DOE/TIC-4500. 